AT the autumn general meeting of the Governors of St. Mungo's College held on Oct. 27th, the Professor of Systematic Surgery, Mr. David N. Knox, M.A., M.B., was appointed Professor of Clinical Surgery in room of Professor William Macewen, LL.D., who had resigned in consequence of his appointment as Professor of Surgery in Glasgow University ; and Mr. Henry E. Clark, M.R.C.S., Professor of Anatomy and Dean of the Faculty of Medicine, was appointed Professor of Systematic Surgery, vice Professor Knox. Appiications for the chair of Anatomy should be lodged with the Secretary on or before Dec. 1st next.

Owivg to the death of Lord Sherbrooke a vacancy has occurred in the Senate of the University of London, and in accordance with precedent his place will be filled by a graduate in science or medicine. Dr. W. J. Collins, M.S., B.Sc., F.R.C.S., is a candidate, and probably other names will shortly be announced.

THE next meeting of the Odontological Society of Great Britain will take place on Nov. 7th, when Mr. Storer Bennett will read a paper on Some Mechanical Devices for the Retention of Artificial Dentures, and a communication will be given by Mr. F. Newland-Pedley on Inverted Lower Canine Tooth erupting below the Chin.

THE Royal Commission on Vaccination held another meeting on Wednesday last, Sir James Paget presiding. Dr. J. C. M'Vail was examined and gave evidence in favour of vaccination. The Commission then adjourned until Wednesday next.

THE Royal Medical Benevolent College has received a donation of $£ 1000$ from a friend who does not wish his name to be known.

Professor VIRCHow has been appointed an honowary member of the Imperial Russian Natural Philosophy Society.

\section{HOSPITAL FEDERATION IN LONDON FOR CLINICAL PURPOSES.}

By JoHN ERIC ERICHSEN, LL.D., F.R.S., F.R.C.S. \&c.

Iv the Report of the Royal Commission on a Teaching University in and for London it is stated that the opportunities for clinical instruction that exist in the metropolis are "unrivalled." That this is so admits of no doubt, and that these unrivalled opportunities are not utilised to anything like their full extent is equally certain. No evidence was given before that Commission to show how these admittedly unrivalled opportunities could be utilised with more advantage to the student than they now are, and the report is silent on this most important point. I trust that I may therefore be excused for venturing to make some suggestions towards the attainment of so desirable an end. I have visited at various times most of the great medical schools in Europe and in the United States of America, and I can without hesitation affirm that the word "unrivalled," used in the Report of the Royal Commission as descriptive of the clinical opportunities presented by London, is the correct designation. No city in the civilised world offers such a wealth and so varied an abundance of clinical material as does London, both as regards general medical and surgical practice and particular forms of special disease, and yet so little are these unequalled opportunities utilised that English medical students annually resort in large numbers to the cliniques of Paris, Vienna and Berlin in order to obtain that professional knowledge to which access is denied them in this metropolis. They can there follow without restraint and at little or no cost the teaching of the most eminent physicians and surgeons and of the most able specialists of the day. They return skilled in foreign methods of diagnosis and of treatment, but with little knowledge of those that are to be learnt in this great city, outside the walls of the particular hospital in which they have bcen educated; for to the vast and varied stores of clinical information that here lie within easy reach access is practically denied, and indeed of their very existence they may be ignorant. 'The student is obliged to go abroad for the purpose of obtaining advanced and special clinical in. struction, not from any lack of material here, but in consequence of its inaccessibility and the absence of all proper organisation for its study and utilisation. In London he is absolutely restricted to the teaching of the physicians and surgeons of the one particular hospital to which, as a pupil, he has attached himself and for which he has paid his fees. The invaluable instruction to be gained from the vast practical experience and profound scientific attainments of such teachers as a Jenner or a Gull, a Paget or a Lister, or the skill to be acquired by being the daily witness of the con. summate methods of a Liston, a Fergusson, or a Bowman, are denied him here unless he happens to have entered as a pupil to the hospital to which one or other of these masters of their science and art is at the time attached. To the practice of that one particular man he is admitted. From that of the others he is shut out, unless he possesses the means and has the inclination to pay a second or a third time the very considerable fee for " hospital attendance." This, indeed, is a student's question, and the matter should be considered from a student's point of view rather than from that of the teacher in the medical school or the governor of the hospital. The London student has a right to expect that he shall not be placed at a disadvantage by the refusal freely to open to him those vast stores of clinical observation and study that are to be found in such unequalled and profuse abundance in London, and thus to be compelled either to starve his craving for knowledge if he remains here or to satisfy it at the cost of going abroad. There is no other alternative. But may not this state of things, so injurious to the best interests of medical education, be corrected? Is it not possible to place London not only on a level with but far ahead of all other European capitals, as a great school of clinical medicine and surgery in the widest sense of clinical teaching as well as in its more special departments? I cannot doubt that with proper organisation of the enormous opportunities for clinical study that exist in London, and by rendering these accessible to the advanced student and young practitioner, the necessity for foreign study will no longer be felt, and that the cliniques of London will attract in their turn students not only from all parts of the United Kingdom, but from our colonies, the United States of America and even the Continent of Europe. Those who may wish for special opportunities of study and of instruction in every department of clinical medicine and surgery will come here, and the cliniques of London will be placed in that pre-eminent position which their physicians and surgeons have so long and so ably maintained. The value of a clinique is determined by three considerations. These are : first, the amount of clinical material ; second, the character of the cases ; and third, the ability of the teachers. Few, even amongst the members of the medical profession, are probably aware of the immense amount of clinical material that exists in London. The vast number of diseased and injured persons of the class that seeks cure and relief in our hospitals, infirmaries and medical charities of all kinds far exceeds that of any other city in the world. The population of the county of the city of London equals in numbers that of the whole of Scotland and exceeds greatly that of many continental Sovereign States. Engaged in every possible kind of industrial pursuit hazardous to life or limb, and injurious in many special ways to health, it would of necessity furnish an enormous amount of injury and disease. To this must be added a very large number of persons suffering from serious or special forms of disease who are constantly attracted to London from all parts of England, and even from the colonies, by the world-wide reputation of its hospitals, both general and special, and by that of individual members of their staffs.

There are eleven general hospitals in London of sufficient size to be recognised by the Royal Colleges as schools of clinical medicine and surgery. In these eleven clinical hos. pitals there is a total of 4542 beds. ${ }^{1}$ The number of beds varies greatly, from 750 in the largest to 180 in the smallest of these hospitals. Besides these there are several smaller general hos. pitals, such as the Great Northern, the Metropolitan, the West

1 This number is taken from the list published in the British Medical Journal for Sept. 3rd, 1892. 
London and the North-Western Hospitals, which, although not recognised by the Examining and Licensing Corporations as schools of medicine, afford abundant opportunities for clinical study and the acquirement of practical experience. The amount of clinical work done at a hospital cannot be measured solely by the number of its beds. The out-patient departments which have now grown to enormous and almost overwhelming proportions in all the London hospitals furnish an abundant supply of interesting and instructive cases, more particularly of various special forms of medical and surgical disease which do not require to be treated in hospital-such as affections of the eye, the ear, the skin and the throat-for which special cliniques are now established in all the larger general hospitals. In addition to these there are special departments in the general hospitals for the treatment of diseases of women and children, and to all a maternity charity is also attached. The Poor-law infirmaries in the metropolitan area are very numerous and contain a vast number of beds. I find on reference to Churchill's Medical Directory for 1892, the most reliable source of information on such a subject, that there are no less than twenty-seven such infirmaries, containing an aggregate of 13,285 beds, or an average of nearly 500 beds. These are, in fact, general hospitals, and contain an immense amount of clinical naterial that now goes to waste, but that admits of being most advantageously utilised. Of its great value I can give no better proof than that of the work done by Sir Henry Thompson, who, when surgeon to the St. Marylebone Infirmary at the commencement of his brilliant career, made there a series of researches on the Diseases of the Prostate of the most important character; whilst his preclecessor, Mr. Benjamin Phillips, F.R.S., found in the wards of the same infirmary the material which served as the basis of his work on Scrofula. These infirmaries contain nexhaustible material for the study of the diseases of 3dvanced life, of childhood and of many special forms of disease, such as those of the skin. In early professional life I was a frequent visitor to the wards of the St. Marylebone Infirmary, which was then officered by Dr. Mayo, President of the Royal College of Physicians, Dr. Glendinning and Mr. Benjamin Phillips, F.R.S., and learnt much in them of diseases that are not usually met with in general hospitals. The special hospitals of London are very numerous. They are of two kinds : those that have been established by the benevolent public to fill a gap and a recognised want in the other charitable institutions, and those that have been founded by and, to use an American expression, are "run" by special practitioners. For obvious reasons such institutions as the latter are not suited for educational purposes or as schools for clinical instruction. But the special hospitals that belong to the first category are numerous, large, well equipped and officered by physicians and surgeons of the highest eminence and of acknowledged ability in their respective special lines of practice.

It would be impossible here to mention all the special hospitals that exist in London and might be made available for clinical instruction. But a few of the most important may be specified. Thus the seven "fever" hospitals for the reception of acute zymotic diseases contain (1892) a total of 2571 beds, often greatly augmented in periods of the prevalence of epidemics, as of typhoid or scarlet fever. ${ }^{2}$ The two largest hospitals for diseases of the chestviz, the Brompton Hospital for Consumption and the City of London Hospital-contain respectively 321 and 164 beds. The Moorfields Ophthalmic Hospital contains 100 beds, but as the vast majority of cases of eye disease admit of being treated as out-patients, it is in its external clinique rather than in its in-patients that the measure of its utility as a clinical school is to be found. The Cancer Hospital contains 120 beds and the Lock Hospital 155 . Both these institutions contain valuable material for clinical study. There are at least eight special hospitals for children, containing an groregate of 621 beds. Of these eight hospitals, two-viz., the hospital in Great Ormond-street, with 175 beds, and the East London Hospital, with 102-would be available for purposes of clinical instruction. There are five hospitals for diseases peculiar to women, containing an aggregate of 241 beds, which are chiefly devoted to the reception of patients suffering Erom diseases requiring surgical treatment. In addition to these there are eight lying-in hospitals. The National

2 At the present time (October, 1892) these hospitals contain over 1000 cases of scarlet fever, diphtheria and typhoid fever.
Hospital for the Paralysed and Epileptic, in Queen-square, contains 175 beds, and is now thoroughly equipped for clinical instruction. There is one special hospital which I believe to be peculiar to London-I mean the Poplar Hospital for Accidents, an institution rendered necessary by the hazardous work carried on in its neighbourhood. It contains 51 beds. There is thus in the general and special hospitals alone an aggregate of from 8000 to 9000 beds available for clinical purposes. The asylums for idiots, imbeciles and lunatics are very large, The fire asylums for idiots and imbeciles contain an aggregate of 6750 beds. Bethlem and St. Luke's Hospitals contain a total of over 500 beds, and the five public lunatic asylums specially connected with the metropolis have an aggregate of 12,705 beds.

In addition to the vast amount of clinical material that exists in London in its various large general hospitals, its infirmaries, its more important special hospitals, its maternities and its asylums for the idiotic and insane, and which might all be made available for the purposes of study and of instruction, there is much more to be found in the smaller hospitals and in the dispensaries which abound in the metropolis. These institntions, though highly useful for the purposes of private study and observation, are neither officered nor equipped in a manner that would render them available as clinical schools. They have accordingly been left entirely out of present consideration. It is not only the amount of the material available for clinical instruction that has to be taken into consideration in estimating the value of a clinique; its character must also be taken into account, and in this respect London will be found to be as far beyond all rivals as in the mere number of its patients. By the character of the clinical material I mean the importance of the cases of which it is composed, either as regards severity or rarity, or as presenting typical forms of disease. The high reputation of the metropolitan hospitals and the acknowledged eminence of many members of their staffs have always attracted a large number of persons suffering from the more serious, special or incurable forms of medical and surgical disease to seek advice in the metropolis. This number has been largely increased of later years by the facility and cheapness of transit. Many provincial practitioners also prefer to send their more important cases for adrice and operation to their old hospital and their old teachers in London, on whose judgment and skill they have reliance and with whose views they are acquainted. A considerable percentage of the inpatients in the London hospitals thus comes up to London for advice and operation. I find that at University College Hospital-with the details of which in this respect I am only acquainted-the proportion of the in-patients who come or are sent up from the provinces amounts as nearly as possible to 10 per cent. of the whole. But there is another potent factor in raising the standard of gravity in the in-patients of many at least of the London hospitals. It is their acknow. ledged insufficiency in point of accommodation for all of those who seek their aid. Hence a strict process of selection is adopted by the resident officers in the admission of patients, and only the most severe, urgent and important cases are admitted, all of those who can in any way be treated in the out-patient department and most of the chronic cases being referred to it.

of the professional eminence and the special aptitude for teaching of the large body of distinguished physicians and surgeons connected with the London medical schools I need say nothing, as they are universally recognised and are beyond dispute. There is thus every element for the formation in London of the most important school of clinical medicine and surgery in the world. But to do this the material at hand must be organised and rendered accessible to the student. We will now consider how this can be done. The available clinical material that exists in London may be arranged in three groups of institutions - viz., the general hospitals, with medical schools attached, the larger and more important special hospitals, and the poor-law infirmaries and asylums. Of these, the eleven large general hospitals with their 4542 beds, their special departments and their maternities are by far the most important. They are the most important not only on account of the number of beds they contain and the character of the cases that fill those beds, but of the acknowledged eminence as practitioners and teachers of the oreat body of physicians and surgeons attached to them. Taken collectively and federated together, so that the instruction given in them should be opened to the advanced student they wonld constitute a great elinical school of medicine and of surgery in all their branches that would be without an 
equal in Europe. In this case union is strength. Taken collectively they are superior to all. But their weakness lies in their isolation, for, taken singly as separate and distinct clinical schools, many of them are inferior as regards number of beds, construction and equipment to some of the great provincial hospitals in this country, and none, not even the largest and most important, can claim superiority as clinical schools over those of the capitals and great cities of the continent of Europe or in the United States of America. The remedy is to be found in the abandonment of the system of isolation that at present exists, and which neutrilises the immense and undoubtedly unrivalled opportunities for clinical study that are to be found in the great hospitals and other medical charities of London. For this should be substituted a system of federation for clinical purposes. For it is idle to speak of these opportunities as being "unrivalled" so long as the most important of them are cut up into as many distinct and separate fragments as there are hospital schools in the metropolis, and the remainder are scarcely, if at all, utilised; so that for all purposes of clinical instruction each hospital school is as completely separated from its neighbour as if it were at the Land's End or at John o' Groats house. Unless a system of federation for clinical purposes be substituted for that of isolation and the unrivalled opportunities that I have shown to exist be fully utilised so as to be brought collectively within reach of the advanced student and young practitioner, the medical school of London, great as it undoubtedly is, will never take that pre-eminent position which it is entitled to assume amongst the schools of Europe both by the acknowledged ability of its teachers or the immensity of its clinical opportunities. The system that at present exists in London is so well known as scarcely to require description. It is as follows :--The student "enters" to one particular hospital and continues a pupil of it till he has passed his examinations. He is limited to the practice of that hospital and to the clinical instruction of the medical staff connected with it. The fees that he has paid for these privileges are considerable, and he is shut out from attendance on the practice or the clinique of any other hospital unless he chooses to "enter" it and to pay another fee for clinical instruction. This, I need scarcely say, is very rarely if ever done. He continues througb life, as a rule, attached to his own hospital, with the traditions of which he is imbued and with the practice of which alone he is acquainted. 'The choice of the hospital preferred by the pupil is usually determined by convenience of locality, or by some personal acquaintance with a member of the staff or some former student, rather than by any special regard to the merits of the particular hospital as a place of instruction, of which probably neither he nor his friends are competent judges. The evils arising from this condition of things are not felt in the earlier part of the student's career, but they become manifest later on. The five years' curriculum now required by the licensing corporations may be carried on anywhere, at any medical school in London or the provinces. Any medical school that is recognised by the Royal Colleges may be taken to be fairly equipped, and its teaching fully sufficient for carrying the pupil through his education up to a good minimum pass examination, such as that of the Conjoint Board or the M.B. of most British universities.

My remarks therefore do not apply to the pupil who is preparing for his examinations, but to the student in the subsequent and more important part of this career when qualifying for the M.D. degree or seeking to perfect his knowledge. Indeed, I consider it to be very important that the study leading up to the pass examinations should be carried on at one medical school only and under one set of teachers. The same subjects are taught in all the medical schools and cannot vary. But the method of teaching these subjects and the manner in which they are bandled vary greatly, and this is true not only with regard to subjects that admit of much difference of opinion, but even of such as ordinary descriptive anatomy, which are little more than a mere collection of facts to be committed to memory. By going from one school to another the pupil would have to change his method, which would result in much confusion and loss of time. That faculty of sustained attention, also so important, but also so difficult of attainwent by the young, would be likely to suffer. In any scheme of federation the larger and more important special hospitals-such as those I have already mentioned-should be included. Much valuable information is to be obtained in them in respect to the diagnosis and detail of trcatment of the class of cases with which each hospital is specially con- cerned. Much is to be learnt by the advanced student in the opportunity he would there have of observing and comparing large numbers of cases of allied diseases, and he would be able to do this under the most favourable circumstances, ae many of the physicians and surgeons of the special hospitals are skilled and experienced teachers in the general medical' schools. The twenty-seven Poor-law infirmaries offer-as has already been said -enormous and varied opportunities for clinical study. But their organisation and admission inta any general scheme of medical education would be attendec by some difficulties, owing to the nature of their gorernment, and I would defer the consideration of this part of the subject to some other time, contenting myself for the present with merely pointing out the vast amount of clinical materia stored up in these 13,285 beds, and in the vast opportunities for the study of mental diseases afforded by the great lunatio asylums in and around the metropolis. The establishment in London of a Teaching University to which the medical schools would be attached as constituent colleges would be a most favourable occasion for the federation (for clinical purpose) of the hospitals connected with those schools, and for the mutual interchange of students during the final two years preceding the examination for the M.D. degree, under certain restrictions to be agreed upon by the colleges and the Council of the University. The scheme that I would venture to suggest for the purpose of hospital clinical federation is briefly as follows: On the admission of a medica? school as a constituent college of the new Teaching University it should become a member of the hospital federation. The admission of any given school as a constituent college would be voluntary, but a condition of such admission should be that it become federated, so far as advanced clinical hospita? instruction is concerned, with the other constituent medical colleges. The federated hospitals should be open for the purposes of clinical instruction to all those students who intend to present themselves for examination for the M.D. degree of the new university, no student being admissible to such instruction until after having obtained a registrable qualification and only during the final period of two years of study; no student in statu pupillari being admissible to any other instruction than that which is given at his own particular hospital. Admission to the clinical in struction of the federated hospitals should be by ticket, to be issued by the university, for which no fee should be paid by London students beyond a small one, say of ons guinea, to meet the expense of registration and to ensure the bona fides of the applicant. In the case of the provincia? students who had not previously entered to the practice of any of the metropolitan hospitals an entrance fee should be paid to the university, the amount and disposal of which max from time to time be determined by the Council; or, by entering directly to the practice of one of the federated hos pitals, he would be placed in the same position as a London student. In the case of the special hospitals that havs become federated a small fee should be charged, such as is now paid for attendance on post-graduate classes, and as attendance on these hospitals is now recognised by the Royal Colleges as part of their five years' curriculum, no dificulty need be anticipated here. Special arrangements would require to be made with the metropolitan infirmaries and asylums for the admission of a limited number of students to their practice and residence in an official capacity in these institutions, and at the larger federated special hospitals might be held to count for a part at least of the final two years' clinical study. The requirement from the candidatea for the M. D. degree of a residence in London and attendance for a period of two years at one or more of the colleges of the new Teaching University of London is in strict conformity with the rule of every other teaching university in Great Britain. 'The four Scottish universities all require residence as ar essential preliminary to admission to examination for their degrees. So likewise do the four teaching universities of England. On what ground, therefore, can this be refused in the Teaching University for London? If the principle of residence be right for Edinburgh and Glasgow, Aberdeen and St. Andrews, for Oxford and Cambridge, Durham and Man. chester, how can it be wrong for London? If not necessary for the London student, on what ground can its necessity be urged for those of other universities of a similar scope as that for London? The M.D. degree should not be given before the age of twenty-four, two years subsequently to the time at which the registrable qualification has been obtained. These two years should be deroted to the attainment of proficiency in clinical medicine in tho 
federated hospitals and to the practical subjects connected with it. Two years so spent would be undoubtedly the most important in the career of the student.
When once he has emerged from his pupilage and has When once he has emerged from his pupilage and has his mind of a vast amount of detail with which it has been encumbered for the purposes of passing successfully the dreaded ordeal of the various examinations leading up to the attainment of his diploma, and he is then free to devote himself specially to clinical medicine and to such other scientific and practical work for which he may have special aptitude or natural inclination. The whole of the day cannot, and need not, be spent in clinical study and observation. Much time should be given to it, but much may also be reserved for practical study and work in the laboratories of physiology, pathology, bacteriology, hygiene and forensic medicine. These scientific departments of medicine should occupy his attention as well as clinical medicine, for in them should his examination for the M.D. be conducted, and to proficiency in them must he look for success as a scientific practitioner in future life. In the study of such subjects as those which are comprised in what are termed "postgraduate" courses the student will find the most useful and profitable employment during the final two years that should intervene between his ordinary "pass" and his ultimate M.D. examination. He will now have been emancipated from his own particular school-from that school of medicine in which be has received his education up to the period of his pass and he will naturally seek for instruction in the higher and more scientific branches of his profession wherever the fame of the teachers is highest and the equipment of their laboratories the most complete. Should this be in his own school he will naturally remain there. Should superior attractions and opportunities present themselves elsewhere he will-if wise - not allow himself to be fettered by old ties and traditions, but get the best instruction from the best beachers and in the best equipped laboratories, wherever they are to be found. He will find that every clinical school presents some special distinctive feature or method of its own, differing perhaps widely from that to which he has heretofore been accustomed, but well deserving careful study and comparison. His horizon will be widened. He will learn no longer jurare in verba magistri, but to form juster conceptions in science and to take broader views in practice than he possibly could when confined to the narrowing influences of the teaching of one set of men and the traditions of one hospital only, and be will be led to form a clear and considerate judoment on men whose opinions, though differing from those of his own teachers, he may yet find not to be entirely erroneous or andeserving of consideration.

\section{THE THIRD REPORT OF THE LORDS' COMMITTEE UPON METROPOLITAN HOSPITALS.}

THE third and final report issued by the Lords' Committee upon Metropolitan Hospitals has now been made public and contains, in addition to a summary of the evidence submittec, the conclusions at which the Committee have arrived. These conclusions are conveniently distributed under a series of keadings, and, although too voluminous for quotation unabridged, may be conveniently summarised as follows :-

\section{ENDOWED Hospitals.}

In the case of the three endowed hospitals, the Committee are of administration does not on are favourably with that which exists at the other general hospitals.
ti throws too much power and responsibility into the hands of one it throws too much power and responsibility into the hands of one individual, the treasurer; though at St. Thomas's Hospital a larger
share in the administration is assigned to committees than at the other share in the administration is assigned to committees than at the other
two. The Committee would suggest that in all these endowed hospitals the government should be carried on by a sy stem of weekly boards and 3rbeommittees.

\section{ReMaining Genfral Hosprtals aNd Schoors.}

Their systems of management greatly resemble one another, and the evidence shows that they are generally well administered The Comtyanagers and the care exercised, so far as the Committee are able to judagers and the care exercised, so far as the Committee are able to
judge, in the appointment of their medical as well as other officers. The Committee desiue to refer to the personal nnrsing dispute appearing in the evidence of the London Hospital. The authors of these charges were for some time nurses and probationers in this hospital, some of whom did not remain during the whole period of training,
and of whom two at least stated grievances of the ir ow a which were and of whom two at least stated grievances of the ir ow n which were
not confirmed by the evidence; and the late chaplain, who for some time before the termination of his connexion in tbat capacity with the hospital, had differences with the Commitiee both in these matters and also in regard to the performance of his own duties. The charges are
on the whole, in the opinion of the Committee, not substantiated by in the whole, in the opinion of the Committee, not substantiated by
the evidence. The evidence in regard to the injury to the health of the "sisters" appears inconclusive. The Committes consider that the "sisters" appears inconclusive. The Committe consider that the difficulties would have been avoided had the Governing Board in
charge of the hospital at that time not allowed their authority to fall charge of the hospital at that time not allowed their authority to fall
into the hands of salaried officers. In justice, however, to the London into the hands of salaried officers. In justice, however, to the London
Hospital, the Committee wish to add that it is an admirable hospital, Hospital, the Committee wish to add that it is an admirable hospital, doing work in a part of London where it confers inestimable benefts upjn a very large and very poor population. They theretore think it
is deserving of the greatest measure of charitable support. The Com. is deserving of the greatest measure of charitable support. The Com.
mittee recognise that it is advisable, under present circumstances, to maintain the individuality of these general hospitals, and they consider hat the generous rivalry thus promoted tends to medical and administraive efficiency. The Committee suggest that the fact of not holding
the diplomas of the Royal Gollege of Physicians and Royal College of the diplomas of the Royal Gollege of Physicians and Royal College of Surgeons of London should not exclude practitioners who have
raduated elsewhere from becoming members of the staffs of the general hospitals in London.

\section{Conyalescent Homes} The Committee remark that the accommodation for convalescents in
connexion with the large hospitals is insufficient, only two or three having convalescent homes attached to them : and that this want is met by the authorities of the hospitals subscribing. through the Samaritan Fund, to convalescent homes Owing to the scarcity of accommodation the patients, although not thoroughly cured, are dis. charged if well enough to leave the hospital. In some cases these patients find their way to the Poor-law inflrmaries: in otber cases patients suffering from medical complaints bave to be kept for long periods in a hospital, although they would recover more rapidly at a convalescent home in the countrv. Moreover, these patients have to
be provided for in the hospital, to the exclusion of those who would be admitted were beds vacant. The Committee avail themselves of this opportunity to direct attention to this need, in the hope tbat more exeffort.

OUT-PATIENTS aNd DISPENSARIES.

It is concidered by the Committee that by the abolition of the outpatent departments medical education would be seriously interfered w'th, and, fur ther that on the whole it must be left to the authorities of the hospitals themselves to arrange the organisation of the outpatient department with the view of rapidly atcending to the requirements of the public and of insuring as far as they can that the arities shall not be abused. The Committee are of opinion that the $\mathrm{ch}_{\text {zrities }}$ are not abused to any serious or appreciable extent, nor do they think that it was by any means proved that patients are carelessly reated, or ts eated by students instead of thoroughly qualifed medical practitioners. On reviewing the evidence as to the different systems pursued by the different great general hospitals the Committee think that, on the whole, the syste $m$ of limiting the number of out-patients per diem s the most convenient. The Lommittee consider that inquiries should be and wherever experienced cfficials think there is cause for suspicion, reliuf. Medical practitioners and the medical nfficers of free and other dispunsaries should be encouraged as much as pussible to take advanige pf out.patient depertments as ant for ponsultatire purposes and from the evidence of $m$ iny hospital witnosses and others, this is already fone to evidence on ing hospital witnosses and others, this is already the patient might be left in the hinds of his medical adviser and not necessarily taken into the hospital.

\section{Distribution of Hospitals.}

It was suggested that certain hospitals might be removed from places where they are not so much required to localities where the accom modation is atficient. The Committee cannot regard this suggestion as practical, but they would strongly advise that more hospital accom modation shnuld be provided south of the Thames, and were it possible to find the site, and were philanthropic ende tvours to be made for further accommoda ion for the sick in London, a large general hos. pical, say in the densely populated district of Camberwell, would so doubt be of extreme value.

The Committee observe that a very useful field for medical instruc. tion is at present closed to students-namely, the Poor-law infirmaries. It was the opinion of nearly every witness that these infirmaries could he usefully opened for clinical instruction. In this the Comnittee heartul concur. In addition to the large field for instruction which would thus be opened, they agree with the opinions expressed that the presence of students is to the practitioners stimulating, by reason of the observation and criticism which are brought to bear on diagnosis and treatment; and the evidence they have received shows that where the patients have no objection to students at their bedsides.

\section{Spectal Hospitals.}

Hospitals for certain diseases of patıents-for example, for childrendo not appear to the Committee to be open to the criticisms made on special hospitals lock hospitals form a sep zrate subject for considerat on. The Committee think that the nature of the disease and the character of the patients make it desirable th it they should be treated in separate buildiugs, or, at all events, in separate wards from other patients. The Committe have had their attention particularly directed to the fact that patients in these hospitals are in the habit of quitting the he hospital in a diseased state on such oc casions as the Derby week, recommend that provisions analogous to those which prevent a patient recommend that provisions analogous to those which prevent a prient leaving a hospiti when sufrering under infectious disea consider that the charge of abuse is substantiated in regard to some small special the charge of abuse is substantiated in regard to some small special hospitals. This class of small special hispitals to which the Committte rifer, of which examples ap Jear in the evidence, the committee do not consider of any real benefit either to the sick or to science Ther appear to be carried on sometimes in incommodious buildings or nnder insanitary conditions, and the
plication of such institutions. 